\title{
Strategi Pengurangan Tingkat Pengangguran dengan Mengetahui Korelasi Tingkat Pertumbuhan Ekonomi dan Tingkat Angkatan Kerja di Kabupaten Bondowoso ${ }^{1}$
}

\section{A Strategy to Reduce the Unemployment Rate by Knowing the Correlation Between the Level of Economic Growth and the Level of the Labor Force in Bondowoso District}

\author{
Sonia Nuri Aprilia ${ }^{\mathrm{a}}$, Ratri Wulandari ${ }^{\mathrm{a}}$, Nizar Qomarodin ${ }^{\mathrm{a}}$ \\ a Program Studi S1 Perencanaan Wilayah dan Kota, Jurusan Teknik Sipil, Fakultas Teknik, Universitas \\ Jember, Jl. Kalimantan 37 Jember
}

\begin{abstract}
ABSTRAK
Pertumbuhan ekonomi sering dijadikan acuan sebagai indicator keberhasilan ekonomi di suatu wilayah. Indikator tersebut salah satunya adalah terkait pengangguran. Pengangguran merupakan suatu permasalahan serius yan harus ditindaklajuti oleh pemerintah Kabupaten Bondowoso untuk mencapai kesejahteraan masyarakat dan keberhasilan ekonomi daerah. Tujuan penelitian ini adalah untuk mengetahui pengaruh pertumbuhan ekonomi dan tingkat angkatan kerja terhadap tingkat pengangguran dan merumuskan strategi pengurangan tingkat pengangguran di Kabupaten Bondowoso. Dalam penelitian ini dilakukan dengan menggunakan analisis korelasi untuk megetahui hubungan antar variable yaitu variable pertumbuhan ekonomi dan tingkat angkatan kerja. Dilanjutkan dengan analytical hierarchy process (AHP) untuk mengetahui variabel yang menjadi prioritas dalam penelitian ini. Hasil penelitian ini menunjakkan bahwa: Hasil analisis korelasi berdasarkan nilai Sig. (2-tailed) dan correlation pearson diketahui bahwa antara variabel pertumbuhan ekonomi dan angkatan kerja dengan jumlah pengangguran tidak berhubungan. Namun, karena $\mathrm{r}$ hitung atau pearson correlations dalam analisis ini bernilai positif maka itu artinya hubungan antara kedua variabel tersebut bersifat positif (+) atau dengan kata lain semakin meningkatnya pertumbuhan ekonomi dan angkatan kerja maka akan meningkatkan pula jumlah pengangguran. 2) Berdasarkan hasil Analitycal Hierarchy Process (AHP) untuk mengetahui faktor prioritas yang berpengaruh signifikan terhadap jumalah pengangguran, diketahui bahwa faktor prioritas yang berpengaruh signifikan terhadap jumlah pengangguran adan kualitas sumber daya manusia. 3) Berdasarkan faktor prioritas yang berpengaruh signifikan terhadap jumlah pengangguran, maka dapat dilauka upaya dalam mengurangi jumlah pengangguran di Kabupaten Bondowoso antara lain mengadakan pelatihan kerja, pengembangan dan bimbingan usaha secara mandiri, meningkatkan mutu pendidikan, dan meningkatkan hubungan antara lembaga pendidikan dan industri.
\end{abstract}

Kata kunci: Pertumbuhan Ekonomi, Angkatan Kerja, Pengangguran

\begin{abstract}
Economic growth is often used as a reference as an indicator of economic success in a region. One of the indicators is related to unemployment. Unemployment is a serious problem that must be followed up by the government of the Bondowoso Regency to achieve community welfare and regional economic success. The purpose of this study was to determine the effect of economic growth and labor force levels on the unemployment rate and formulate a strategy to reduce the unemployment rate in Bondowoso Regency. This study conducted using correlation analysis to determine the relationship between variables, namely economic growth variables and labor force levels. Followed by the analytical hierarchy process (AHP) to find out which variables are the priority in this study. The results of this study show that: The results of correlation analysis are based on Sig. (2-tailed) and Pearson correlation is known that between the variables of economic
\end{abstract}

${ }^{1}$ Info Artikel: Received: 30 Desember 2019, Accepted: 14 Januari 2020 
growth and labor force with the number of unemployed are not related. However, because the $\mathrm{r}$ arithmetic or Pearson correlations in this analysis are positive, it means that the relationship between the two variables is positive (+), or in other words, increasing economic growth and the labor force will also increase the number of unemployed. 2) Based on the results of the Analytical Hierarchy Process (AHP) to determine priority factors that have a significant effect on the number of unemployed people, it is known that priority factors that have a significant effect on the number of unemployed and the quality of human resources. 3) Based on priority factors that have a significant effect on the number of unemployed, efforts can be made to reduce the number of unemployed in the Bondowoso District, including conducting work training, developing and guiding business independently, improving the quality of education, and improving relations between educational institutions and industry.

Keywords: Economic Growth, Workforce, Unemployment

\section{PENDAHULUAN}

Pembangunan ekonomi menjadi salah satu tujuan utama negara berkembang yang tidak hanya berkaitan dengan pertumbuhan ekonomi tetapi juga berfokus pada peningkatan kesejahteraan masyarakat dan kualitas sumber daya manusia. Masyarakat adalah salah satu pelaku pembangunan yang menjadi unsur utama dalam pembangunan dan memiliki keterlibatan dalam pertumbuhan ekonomi. Pertumbuhan ekonomi sering menjadi acuan sebagai indicator keberhasilan perekonomian di suatu wilayah. Karena pertumbuhan ekonomi yang tinggi dapat mengurangi pengangguran di wilayah tersebut dalam artian pertumbuhan ekonomi akan berbanding lurus terhadap tingkat pengangguran (Nuraini, 2017). Hal itu terjadi karena ketika pertumbuhan ekonomi naik maka proses produksinya akan mengalami kenaikan pula dan dapat menyerap banyak tenaga kerja untuk menghasilkan output yang diminta. Keterkaitan sector ekonomi antar wilayah menjadi salah satu media pendorong pertumbuhan ekonomi wilayah dengan peningkatan jumlah produksi yang dapat menyerap banyak tenaga kerja sehingga berdampak pada pertumbuhan ekonomi secara inklusif dan berkelanjutan (Farizkha, 2013).

Pengangguran merupakan permasalahan kompleks yang sering dijumpai di berbagai wilayah baik di Negara Maju maupun Negara Berkembang, perbedaannya adalah Negara maju dapat memberikan tunjungan kepada masyarakat pengangguran sebaliknya Negara Berkembang tidak dapat memberikan tunjangan tersebut (Sirait, 2013). Tunjungan tersebut diperuntukkan agar masyarakat mendapatkan pekerjaan sehingga program tersebut dapat mengurangi tingkat pengangguran di suatu wilayah. Ketika tingkat pengangguran tinggi maka akan berdampak buruk pada perekonomian, kesejahteraan masyarakat, produktivitas dan pendapatan masyarakat sehingga dapat menimbulkan masalah social seperti kemiskinan, kejahatan, kebodohan, kelaparan, dll.

Berdasarkan Rencana Pembangunan Jangka Menengah (RPJM) tahun 2010 - 2014 telah menetapkan daftar sebanyak 183 kabupaten yang termasuk kategori daerah tertinggal di Indonesia, salah satunya adalah Kabupaten Bondowoso. Permasalahan ketertinggalan di Kabupaten Bondowoso adalah terkait isu kemiskinan, rendahnya kualitas pendidikan, tingginya angka pengangguran, rendahnya produktivitas dan kualitas produksi. Pengangguran di Kabupaten Bondowoso menjadi permasalahan serius yang akan berpengaruh terhadap kualitas sumber daya manusia dan berdampak pada tingkat kemiskinan dan perkembangan perekonomian daerah. Tingkat pengangguran pada tahun 2015 sebesar 8,64\% akan tetapi mulai mengalami peningkatan 2x lipat pada tahun 2018 yang mencapai $15,83 \%$, angka tersebut berada diatas rata-rata pengangguran nasional 
yang sebesar 5,00\%. Kesenjangan tingkat pengangguran tersebut mengakibatkan perkembangan perekonomian di Kabupaten Bondowoso menjadi sangat lambat dan tidak dapat bersaing dengan wilayah lainnya. Jika Kabupaten Bondowoso tidak memiliki daya saing tinggi maka akan tetap menjadi daerah tertinggal. Dengan permasalahan kompleks tersebut maka perlu memperoleh perhatian segera agar tercapai sasaran pembangunan daerah.

Sasaran penelitian ini adalah untuk merumuskan program terkait pengembangan perekonomian dalam upaya mengurangi tingkat pengangguran di Kabupaten Bondowoso. Maka dari itu tujuan dari penelitian ini adalah mengetahui korelasi jumlah tingkat pengangguran dengan pertumbuhan ekonomi dan angkatan kerja, serta perumusan strategi dalam menangani permasalahan pengangguran di Kabupaten Bondowoso.

\section{LANDASAN TEORI}

Pertumbuhan ekonomi merupakan sebuah kewajiban untuk mengurangi kemiskinan, dengan menggunakan syarat pertumbuhan tersebut efektif dalam mengurangi kemiskinan (Siregar, 2006). Artinya, pertumbuhan ekonomi hendaknya menyebar di seluruh golongan pendapatan, termasuk di golongan penduduk miskin. Secara tidak langsung pemerintah harus lebih memanfaatkan pertumbuhan yang boleh jadi modal dari sektor modern seperti jasa dan manufaktur yang padat modal.

Pertumbuhan ekonomi merupakan proses kenaikan output perkapita dalam jangka panjang dengan penekanan pada tiga hal yaitu proses, output perkapita dan jangka panjang (Wijono, 2005). Sebagai contoh pada kenaikan output total PDB dalam jangka panjang tanpa memandang kenaikan tersebut lebih kecil atau lebih besar dari laju pertumbuhan penduduk dan struktur perekonomian. Tolok ukur keberhasilan ekonomi disuatu wilayah dapat dilihat dari pertumbuhan ekonomi dan struktur ekonomi, semakin kecil ketimpangan pendapatan penduduk antar daerah dan antar sektor. Dengan menggunakan 2 indikator diatas dapat dikembangkan menjadi 4 tipologi daerah untuk mengetahui gambaran pola dan struktur pertumbuhan ekonomi di masing-masing daerah (Kuncoro, 2004). Empat tipologi tersebut adalah:

1. Daerah cepat maju dan cepat tumbuh (Hight Growth and High Income): daerah yang memiliki tingkat pertumbuhan ekonomi dan pendapatan perkapita yang lebih tinggi dibanding rata-rata kabupaten atau kota.

2. Daerah maju dan tertekan (High Income but Low Growth) : daerah yang memiliki tingkat pendapatan perkapita yang lebih tinggi, namun pertumbuhan ekonominya lebih rendah dibanding rata-rata kabupaten atau kota.

3. Daerah berkembang cepat (Hight Growth but Low Income) : daerah yang memiliki tingkat pertumbuhan ekonomi yang lebih tinggi, namun tingkat pendapatan perkapitanya masih lebih rendah dibanding rata-rata kabupaten atau kota.

4. Daerah relatif tertinggal (Low Growth, Low Income) : daerah yang memiliki tingkat pertumbuhan ekonomi dan rata-rata pendapatan perkapita yang lebih rendah dibanding dengan kabupaten atau Kota.

Angkatan kerja adalah suatu suatu kelompok penduduk dalam usia produktif ( $>14$ tahun dan $<64$ tahun) yang memiliki pekerjaan. Sedangkan pengangguran adalah suatu kondisi ketika seseorang tergolong angkatan kerja tetapi belum memiliki pekerjaan dan sedang aktif mencari pekerjaan (Nanga, 2001). Terdapat banyak faktor yang mempengaruhi 
tingkat pengangguran, diantaranya adalah tingkat upah, penggunaan teknologi, tingkat pendidikan, fasilitas modal, tingkat kemiskinan, dll.

\section{METODE PENELITIAN}

Penelitian ini dilakukan di Kabupaten Bondowoso, yang merupakan jenis penelitian deskriptif kuantitatif. Jenis data yang digunakan dalam penelitian ini adalah data sekunder. Data tersebut merupakan data kuantitatif yang bersifat runtut waktu (time series) dalam kurin waktu tahun 2015 - 2018. Data tentang ketenagakerjaan dan pertumbuhan ekonomi ini diambil dari Dokumen Kabupaten dalam Angka Kabupaten Bondowoso. Rujukan dan referensi lainnya yang relevan juga digunkan untuk lebih melengkapi pemaparan hasil penelitian, misalnya dari laporan hasil penelitian, jurnal, dan publikasi terkaitnya.

Teknik analisa yang digunakan adalah analisis korelasi. Pengujian ini dimaksudkan untuk mengetahui tingkat korelasi antar variabel. Variaberl terikat atau dependent variable pada penelitian ini adalah jumlah pengangguran tahun 2015 - 2018 di Kabupaten Bondowoso. Sedangkan variabel bebas atau independent variable ada dua variabel yaitu pertumbuhan ekonomi dan angkatan kerja pada tahun 2015 - 2018. Pada analisis korelasi diketahui bahwa:

a. jika Sig. 2 (tailed) $<0,05$ maka terdapat korelasi antar variabel yang dhubungkan. Sebaliknya jika nilai Sig. (2-tailed) > 0,05 maka tidak terdapat korelasi.

b. Berdasarkan nilai $r$ hitung (pearson correlations), jika nilai $r$ hitung $>r$ tabel aka ada korelasi antar variabel. Sebaliknya jika nilai $r$ hitung $<\mathrm{r}$ tabel maka artinya tidak ada korelasi antar variabel.

c. Tanda korelasi, jika menghasilkan tanda negative (-) pada tabel output spss menunjukkan adanya arah yang berlawanan. Sedangkan tanda positif (+) menunjukkan arah yang sama atau korelasi yang searah.

Lalu pada penelitian ini dilanjutkan menggunakan analisis hierarki proses untuk mengetahui variabel prioritas yang menyebabkan jumlah pengangguran di Kabupaten Bondowoso. Sehingga dari analisis tersebut diketahui upaya yang dapat dilakukan dalam mengurangi jumlah pengangguran. 


\section{ALUR PIKIR}

\section{URGENSI PENELITIAN}

- Tingginya tinkat pengangguran di Kabupaten Bondowoso

- Kesenjangan tingkat penganguran yang tinggi di Kabupaten Bondowoso

- Kabupaten Bondowoso yang menjadi tertinggal

\section{TUJUAN PENELITIAN}

- Mengetahui korelasi pertumbuhan ekonomi dan jumlah angkatan kerja dengan tingkat pengangguran di Kabupaten Bondowoso.

- Mengetahui faktor yang paling berpengaruh terhadap tingkat pengangguran di Kabupaten Bondowoso

- Merumuskan rekomendasi dalam menangani faktor yang menjadi penyebab tingkat pengangguran di Kabupaten Bondowoso

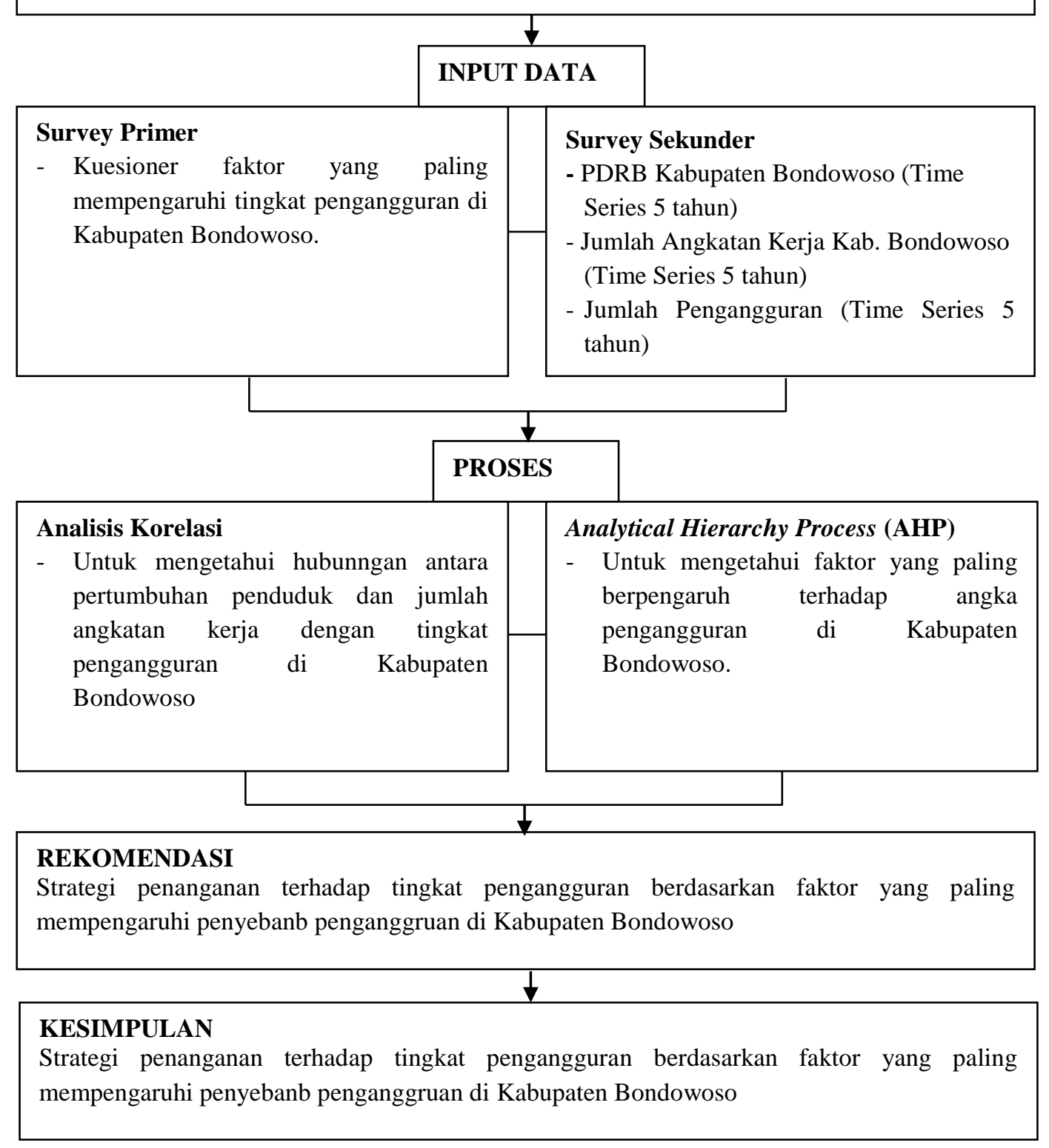




\section{HASIL DAN PEMBAHASAN}

Kabupaten Bondowoso merupakan salah satu kabupaten yang ada di Jawa Timur. Kabupaten Bondowoso merupakan satu - satunya kabupaten di kawasan tapal kuda yang tidak memiliki garis pantai. Kabupaten Bondowoso dengan luas $1526 \mathrm{Km}^{2}$ berdasarkan pembagian wilayah adinistrasi terdiri dari 23 Kecamatan, 209 Desa, 10 Kelurahan dan 1.412 Dusun. Jumlah penduduk di Kabupaten terus mengalami peningkatan, dengan jumlah penduduk pada tahun 2019 sebesar 772.297 jiwa, yang terdiri dari 376.074 jiwa penduduk laki - laki dan 396.223 jiwa penduduk perempuan. Dengan terus berkembangnya jumlah penduduk di Kabupaten Bondowoso juga diiringi peningkatan kualitas sumber daya manusia. Pendidikan merupakan salah satu alternatif dalam upaya peningkatan kualitas sumber daya manusia, yang akan bermanfaat untuk mempelajari keterampilan yang berguna di dunia kerja. Dengan meningkatnya kualitas kerja, maka akan berdampak pada pertumbuhan perekonomian.

Dalam penelitian ini, variabel yang digunakan antara lain adalah jumlah penganguran di Kabupaten Bondowoso tahun 2015 - 2018, pertumbuhan ekonomi Kabupaten Bondowoso tahun 2015 - 2018 dan jumlah angkatan kerja Kabupaten Bondowoso tahun 2015 - 2018. Ketiga variabel tersebut dapat dilihat pada tabel di bawah ini.

Tabel 1 Jumlah Pengangguran di Kbaupaten Bondowoso Tahun 2015 - 2018

\begin{tabular}{|c|c|c|}
\hline Tahun & Jumlah Pengangguran & Perkembangan (\%) \\
\hline $\mathbf{2 0 1 5}$ & 11.721 & 86,36 \\
\hline $\mathbf{2 0 1 6}$ & 7.414 & 49,61 \\
\hline $\mathbf{2 0 1 7}$ & 9.286 & 74,86 \\
\hline $\mathbf{2 0 1 8}$ & 17.033 & 158,29 \\
\hline
\end{tabular}

Sumbe : Kabupaten Bondowoso dalam Angka

Pada tabel di atas, diketahui bahwa jumlah pengangguran terendah adalah pada tahun 2016 yaitu sebesar 7.414 jiwa, sedangkan jumlah pengangguran tertinggi adalah pada tahun 2018 sebesar 17.033 jiwa.

Tabel 2 Pertumbuhan Ekonomi di Kabupaten Bondowoso Tahun 2015 - 2018

\begin{tabular}{|c|c|c|}
\hline Tahun & PDRB & Perkembangan (\%) \\
\hline $\mathbf{2 0 1 5}$ & $11.179 .621,13$ & 4,95 \\
\hline $\mathbf{2 0 1 6}$ & $11.735 .586,18$ & 4,97 \\
\hline $\mathbf{2 0 1 7}$ & $12.325 .664,92$ & 5,03 \\
\hline $\mathbf{2 0 1 8}$ & $12.952 .758,66$ & 5,09 \\
\hline
\end{tabular}

Sumber : Kabupaten Bondowoso dalam Angka

Berdasarkan table 2 diketahui bahwa pertumbuhan ekonomi terus mengalami peningkatan selama 4 tahun terakhir dengan perkembangan mencapapai 5,09\%. 
Tabel 3 Jumlah Angkatan Kerja di Kabupaten Bondowoso Tahun 2015 - 2018

\begin{tabular}{|c|c|c|}
\hline Tahun & Jumlah Angkatan Kerja & Perkembangan (\%) \\
\hline $\mathbf{2 0 1 5}$ & 418.784 & 98,65 \\
\hline $\mathbf{2 0 1 6}$ & 424.851 & 100,1 \\
\hline $\mathbf{2 0 1 7}$ & 444.332 & 104,69 \\
\hline $\mathbf{2 0 1 8}$ & 436.530 & 102,93 \\
\hline
\end{tabular}

\section{Sumber : Kabupaten Bondowoso dalam Angka}

Jumlah angkatan kerja di Kabupaten Bondowoso pada tabel 3 terus mengalami peningkatan selama tiga tahun terakhir dan mengalami penurunan di tahun 2018 menjad 436.530 jiwa.

Untuk mengetahui pengaruh pertumbuhan ekonomi dan jmlah angkatan kerja terhadap jumlah pengangguran di Kabupaten Bondowoso dengan menggunakan analisis korelasi menggunakan software SPSS. Data yang digunakan merupakan data selama 4 time series. Hasil pengolahan dapat dilihat dari tabel berikut :

Tabel 4 Hasil Analisis Korelasi

\begin{tabular}{|c|c|c|c|c|}
\hline & & $\begin{array}{l}\text { Pertumbuhan } \\
\text { Ekonomi }\end{array}$ & $\begin{array}{c}\text { Angkatan } \\
\text { Kerja }\end{array}$ & $\begin{array}{c}\text { Jumlah } \\
\text { Pengangguran }\end{array}$ \\
\hline \multirow{3}{*}{$\begin{array}{l}\text { Pertumbuhan } \\
\text { Ekonomi }\end{array}$} & $\begin{array}{l}\text { Pearson } \\
\text { Correlation }\end{array}$ & 1 & 0,784 & 0,791 \\
\hline & Sig. (2 tailed) & & 0,216 & 0,209 \\
\hline & $\mathrm{N}$ & 4 & 4 & 4 \\
\hline \multirow{3}{*}{ Angkatan Kerja } & $\begin{array}{l}\text { Pearson } \\
\text { Correlation }\end{array}$ & 0,784 & 1 & 0,303 \\
\hline & Sig. (2 tailed) & 0,216 & & 0,697 \\
\hline & $\mathrm{N}$ & 4 & 4 & 4 \\
\hline \multirow{3}{*}{$\begin{array}{l}\text { Jumlah } \\
\text { Penganggguran }\end{array}$} & $\begin{array}{l}\text { Pearson } \\
\text { Correlation }\end{array}$ & 0,791 & 0,303 & 1 \\
\hline & Sig. (2 tailed) & 0,209 & 0,697 & \\
\hline & $\mathrm{N}$ & 4 & 4 & 4 \\
\hline
\end{tabular}

Sumber : Hasil Analisis, 2019

Berdasarkan hasil analisis pada tabel di atas, diketahui bahwa berdasarkan nilai signifikansi Sig. (2-tailed) antara pertumbuhan ekonomi dengan jumlah pengangguran adalah sebesar 0,209 >0,005 yang berarti tidak dapat korelasi yang signifikan antara variabel pertumbuhan ekonomi dengan variabel jumlah pengangguran. Selanjutnya, hubungan antara angkatan kerja dengan jumlah pengangguran memiliki nilai Sig. (2-tailed) sebesar 0,697>0,005 yang berarti tidak terdapat korelasi yang signifikan antara variabel angkatan kerja dengan variabel jumlah pengangguran. Berdasarkan nilai $r$ hitung (pearson correlations) diketahui untuk hubungan variabel pertumbuhan ekonomi dengan jumla pengangguran adalah sebesar 0,791 $<0,950$ yang merupakan $r$ tabel, maka dapat disimpulkan bahwa tidak ada hubungan atau korelasi antar variabel. Sedangkan, untuk nilai hitung $\mathrm{r}$ (pearson correlation) antara variabel angkatan kerja dan jumlah pengangguran diketahui sebesar 0,303 $<0,950$ yang merupakan $r$ tabel, maka dapat disimpulkan bahwa tidak ada hubungan atau korelasi antara variabel angkatan kerja dan jumlah pengangguran. Namun, karena $r$ hitung atau pearson correlations dalam analisis ini 
bernilai positif maka itu artinya hubungan antara kedua variabel tersebut bersifat positif atau dengan kata lain semakin meningkatnya pertumbuhan ekonomi dan angkatan kerja maka akan meningkatkan pula jumlah pengangguran.

Dari hasil analisis korelasi di atas, diketahui bahwa kedua variabel yang digunakan tidak berpengaruh signifikan terhadap jumlah pengangguran di Kabupaten Bondowoso. Untuk mengetahui faktor yang berpengaruh secara signifikan terhadap jumlah pengangguran di Kabupaten Bondowoso, dilakukan Analitycal Hierarchy Process (AHP) menggunakan software expert choice. Analisis ini juga menbahkan varibel lain di luar model dan yang tidak diikutsertakan pada analisi sebelumnya. Variabel tersebut diantaranya, upah minimal rendah, lokasi masyarakat bermukim, rendahnya lapangan pekerjaan, dan kualitas sumber daya manusia yang rendah. Hasil pengolahan analisis hierarki proses dilihat dari gambar berikut :

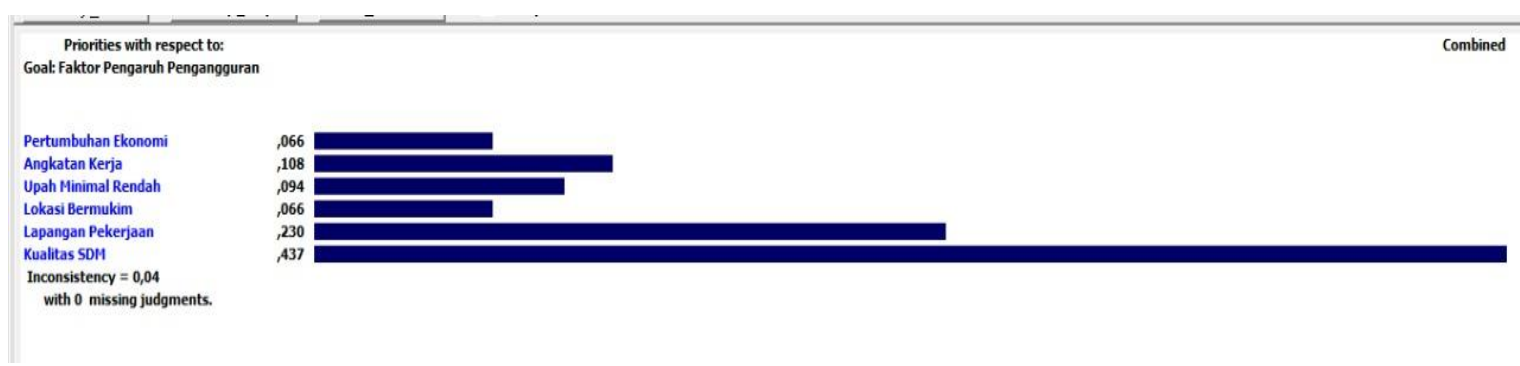

Gambar 1 Hasil Pengolahan Analisis Hierarki Proses

Sumber : Hasil Analisis, 2019

Berdasarkan hasil analisis di atas diketahui bahwa bahwa variabel yang paling berpengaruh terhadap jumlah pengangguran di Kabupaten Bondowoso diakibatkan oleh kurangnya kualitas sumber daya manusia. Maka prioritas penanganan yang dapat dilakukan untuk mengatasi permasalahan pengangguran di Kabupaten Bondowoso adalah peningkatan kualitas sumber daya manusia. Upaya yang dapat dilakukan untuk meningkatkan kualitas sumber daya manusia agar dapat mengurangi jumlah pengangguran di Kabupaten Bondowoso, antara lain :

1. Pelatihan Kerja

Pelatiha kerja dilakukan terhadap masayrakat yang khususnya tidak mempunyai pekerjaan namun skill yang dimiliki kurang memuaskan di dunia kerja dan anak anak yang putus sekolah. Sehingga dengan adanya pelatihan kerja diharapkan dapat meningkatkan dan mengembangkan keterampilan serta keahlian sesuai bakat, minat, dan kemampuan.

\section{Pengembangan dan Bimbingan Usaha Secara Mandiri}

Strategi ini merupakan upaya untuk mengurangi pengangguran terdidik baik di kota maupun di pedesaan melalui pembentukan kelompok - kelompok usaha kecil dengan fasilitas dari pemerintah. Kelompok - kelompok usaha ini perlu dibimbing dan difasilitasi baik dari segi keterampilan berwirausaha, pendanaan manajemen usaha, sampai dengan produk pemasaran dari poduk atau jasa yang dihasilkan. Selanjutnya kelompok usaha mandiri yang dapat berdiri sendiri dan mapan, dapat secara bergantian dan berantai memfasilitasi kelompok usaha baru lainnya.

3. Meningkatkan Mutu Pendidikan 
Semakin tinggi mutu pendidikan maka akan membuat sumber daya manusia yang bekualitas baik juga. Peningkatan kulaitas pendidikan dapat dilakukan dengan penyusunan kurikulum yang dapat menghasilkan lulusan berkualitas serta program wajib belajar. Pendidikan dapat dilakukan untuk menghasilkan generasi - generasi penerus bangsa yang potensial dan merupakan hal yang sangat penting. Maka, hal ini harus diperhatikan pemerintah dalam mengatasi pengangguran.

4. Meningkatkan Hubungan Antara Lembaga Pendidikan dan Industri.

Hal ini perlu dilakukan agar relevensi pendidikan dapat ditingkatkan. Sehingga jumlah angkatan kerja yang telah lulus dari lembaga pendidikan, dapat menerapkan skill sehingga tenaga kerja terserap lebih cepat oleh industri yang ada relevensi dengan lembaga pendidikan yang sebelumnya menjadi tempat menempuh pendidikan.

\section{KESIMPULAN}

Berdasarkan hasil penelitian dapat disimpulkan bahwa: 1) Hasil analisis korelasi berdasarkan nilai Sig. (2-tailed) dan correlation pearson diketahui bahwa antara variabel pertumbuhan ekonomi dan angkatan kerja dengan jumlah pengangguran tidak berhubungan. Namun, karena $r$ hitung atau pearson correlations dalam analisis ini bernilai positif maka itu artinya hubungan antara kedua variabel tersebut bersifat positif (+) atau dengan kata lain semakin meningkatnya pertumbuhan ekonomi dan angkatan kerja maka akan meningkatkan pula jumlah pengangguran. 2) Berdasarkan hasil Analitycal Hierarchy Process (AHP) untuk mengetahui faktor prioritas yang berpengaruh signifikan terhadap jumalah pengangguran, diketahui bahwa faktor prioritas yang berpengaruh signifikan terhadap jumlah pengangguran adan kualitas sumber daya manusia. 3) Berdasarkan faktor prioritas yang berpengaruh signifikan terhadap jumlah pengangguran, maka dapat dilauka upaya dalam mengurangi jumlah pengangguran di Kabupaten Bondowoso antara lain peran pemerintah dalam mengadakan pelatihan kerja, pengembangan dan bimbingan usaha secara mandiri, meningkatkan mutu pendidikan, dan meningkatkan hubungan antara lembaga pendidikan dan industri.

\section{DAFTAR PUSTAKA}

Farizkha, Ivan Agusta dan Santoso, Eko Budi. (2013). Keterkaitan Sektoral di Kabupaten Lumajang. Jurnal Teknik Pomits, II (2), C230-C233.

Kuncoro, Mudrajat. (2004). Otonomi dan Pembangunan Daerah. Jakarta : Erlangga

Nanga, Muana. (2001). Makroekonomi Teori, Masalah dan Kebijakan. Edisi 1. Jakarta : Erlagga

Nuraini, Ida. (2017). Kualitas Pertumbuhan Ekonomi Daerah Kabupaten/Kota di Jawa Timur. Jurnal Ekonomi Pembangunan, 15.

Sirait, Paul A, dan A.A.I.N Marhaeni. (2013). Analisis Beberapa Faktor Yang Berpengaruh terhadap Jumlah Pengangguran Kabupaten/Kota di Provinsi Bali. E-Journal EP Universitas Udayana, II(2) : 108-118. ISSN : 2303-0178

Siregar, H. (2006). Perbaikan Struktur dan Pertumbuhan Ekonomi : Mendorong Investasi dan Menciptakan Lapangan Kerja. Jurnal Ekonomi Politik dan Keuangan. INDEF. Jakarta 
Wijono, Wiloejo. (2005). Mengungkap Sumber-Sumber Pertumbuhan Ekonomi Indonesia Dalam Lima Tahun Terakhir. Jurnal Manajemen dan Fisikal, V(2). Jakarta 